\title{
Knowledge, Attitudes and Awareness about Colorectal Cancer in the Kingdom of Saudi Arabia: A Cross Sectional Study
}

\author{
Nawaf Mohamed Alotaibi ${ }^{1}$, Md Ali Mujtaba ${ }^{1, *}$, Norah Matar Alshammari ${ }^{2}$ \\ 'Department of Pharmaceutics, Faculty of Pharmacy, Northern Border University, Rafha, KINGDOM OF SAUDI ARABIA. \\ ${ }^{2}$ Faculty of Pharmacy, Northern Border University, Rafha, KINGDOM OF SAUDI ARABIA.
}

\begin{abstract}
Background: Colorectal cancer $(\mathrm{CRC})$ is the second most common cancer in Saudi Arabia, ranking first among men and third among women. Colorectal cancer can be easily prevented through CRC screening which can detect the disease during its early stages when the survival rates are high. The aim of this study was todetermine the level of knowledge, awareness and attitudes about colorectal cancer among Saudi people. Methods: A cross-sectional survey was conducted among general population of different regions of Saudi Arabia from $1^{\text {st }}$ of January 2018 to $28^{\text {th }}$ of February 2018. The study questionnaire, containing 25 items, was adapted from surveys identified in the relevant literature. The CRC awareness questionnaire consisted of an awareness section, knowledge section and attitude of participants toward colorectal cancer screening. The data were analyzed by descriptive statistics. Results: A total of 521 general populations answered the questionnaire. Majority of participants (82\%) were bachelor's degree holders and females represent $(60 \%)$. Symptoms such as change in bowel habit, blood in the stool, weight loss and abdominal pain were recognized by only $54 \%, 41 \%, 45 \%$ and $52 \%$ of the respondents, respectively. Common risk factors such as positive family history, obesity and old age were acknowledged only by less than $34 \%, 29 \%$ and $33 \%$ of the respondents. More than one-third of
\end{abstract}

the participants $(45 \%)$ had received information material regarding CRC from their curriculum and by social media and nearly 30\% from other sources such as TV, hospital and mass media. Attitude regarding colorectal screening was positive for $71 \%$, Almost $71 \%$ of the respondents willing to have a screening test for the bowel cancer, even without any symptom. Conclusion: Although majority of the respondents had positive attitude toward concept of cancer screening but their knowledge and awareness about colorectal cancer was low which indicate the need for promotion of cancer education among public.

Key words: Colorectal cancer, Saudi Arabia, Questionnaire, Awareness, Knowledge.

\section{Correspondence}

Dr. Md Ali Mujtaba

Assistant Professor, Department of Pharmaceutics, Faculty of Pharmacy, Northern Border University, Rafha, KINGDOM OF SAUDI ARABIA.

Phone: +966-000-538156614

Email: sajanqa@gmail.com

DOI: 10.5530/jyp.2020.12.73

\section{INTRODUCTION}

Cancer has become a major burden on the health care systems of many countries and is one of the leading causes of mortality worldwide and accounted for over 8.2 million deaths (22\% of all non-communicable diseases deaths) in 2012. ${ }^{1,2}$ Cancer also has a great impact on the social and economic lives of affected individuals. Since the first report of the Saudi Cancer Registry in 1994, the incidence of all cancers, including colorectal, has steadily increased. ${ }^{3}$ Colorectal cancer (CRC) cancer can be referred as a slowly developing cancer which starts as a tissue growth of cancer cell or tumor into the interior facing of the colon. This abnormal growth of tumor known as polyp and then gradually turns into cancer in the wall of colon. This tissue growth subsequently grows into the blood vessels which upsurge the rate of metastasis to other anatomical sites. This type of cancer which start in the mucus generating glands of the colon is commonly distinguished as adenocarcinomas over $95 \%$ cases. ${ }^{4,5} \mathrm{CRC}$ is a common cancer and is ranked as the third in males and the second in females worldwide with approximately one million new cases of colon cancer identified every year and nearly a million deaths. ${ }^{67}$ According to World Health Organization (WHO), in 2015 774,000 numbers of deaths occurred due to this colon cancer while the overall numbers of deaths were 8.8 million worldwide. ${ }^{s}$

Colorectal cancer is the second most common cancer, ranking first among male population and the third among female population in Saudi Arabia. According to the cancer incidence report of Saudi Arabia, 1387 people were diagnosed in Colon cancer in 2013 which accounts for $11.9 \%$ of the overall diagnosed cancer. ${ }^{9}$ It affected $53.1 \%$ of male population within this group and $46.9 \%$ of women were affected in Colon cancer in 2013. This type of cancer becomes the 2 nd most happening cancer type among Saudi individuals of all ages..$^{10}$ This rate is alarmingly increasing and is estimated to leap up to a fourfold increase by the year $2030 .{ }^{11}$ The increase in CRC cases is attributed to several risk factors and by screening; we can also find and remove premalignant adenomatous polyps. Since one of the CRC risk factors is age, most of the international guidelines recommend screening for those aged above 50 years. Other CRC risk factors are family history, obesity, inflammatory bowel diseases and smoking.

Knowing the early symptoms of CRC can avoid the risk factors. Colorectal cancer can be easily prevented through CRC screening which can detect the disease during its early stages when the survival rates are high. ${ }^{12}$ Various methods of CRC screening were developed for early detection and proper diagnosis, hence early management and better prognosis. These screening tools included; non-invasive methods such as stool DNA and fecal occult blood testing (FOBT) and potentially invasive methods such as colonoscopy ${ }^{13,14}$ Colorectal cancer risk factors also included age of patient and most national guidelines recommended screening for those aged 50 years and older. ${ }^{15}$ Most of CRC patients in Saudi Arabia refer at an advanced stage with metastasis which make the treatment difficult and increase the mortality. ${ }^{16}$ In order to create targeted messages and educational material aimed to increase participation in

This is an open access article distributed under the terms of the Creative Commons Attribution-NonCommercial-ShareAlike 4.0 License, which allows others to remix, tweak, and build upon the work non-commercially, as long as the author is credited and the new creations are licensed under the identical terms. 
screening, it is required to understand the levels of knowledge, awareness and attitude of the target population. Poor knowledge of CRC symptoms, risk factors and the benefits of screening programs are potential barriers towards active participation in screening campaigns.Moreover, it has been shown that knowledge of a disease is directly related to screening program participation; thus, the aim of our study was to determine the level of knowledge and awareness of CRC among Saudi people and also to determine attitude toward colorectal screening.

\section{METHODS}

\section{Study participants and data collection}

A cross-sectional survey was conducted from January 2018 to February 2018. The self-administered questionnaire in Arabic language specially designed for the research purpose was loaded on Google drive and sent to random sample of Saudi people living in different regions of Saudi Arabia. The questionnaire measured respondent's knowledge, attitudes, beliefs and behaviors related to the prevention, early detection and treatment of CRC.

The questionnaire contained twenty five questions and divided into 4 main sections: Demographic data, awareness of participants about colorectal cancer, knowledge of participants about colorectal cancer and attitude of participants toward CRC screening. Inclusion criteria included 18 years of age or older, Saudi in nationality and agree to fill the questionnaire. For analyses, education level was grouped as follows: primary education, intermediate education, secondary education and university education. Age was stratified by decade as follows: 18-29 years; 30-39 years; 40-49 years; 50-59 years. Gender and residential status (living in Northern border region, Eastern, Western, Southern and Central region of Saudi Arabia) were also analysed. The score of participants is calculated as percentage; good score level having at least $70 \%$ correct answers.

Collected data was entered to MS Excel version 14.00 and categorical variables were expressed as frequencies. Frequency tables and charts were used for descriptive statistics. The frequency and percentage calculated for all the participants' demographics and answers for the questionnaire with representation for the answers by figures. During

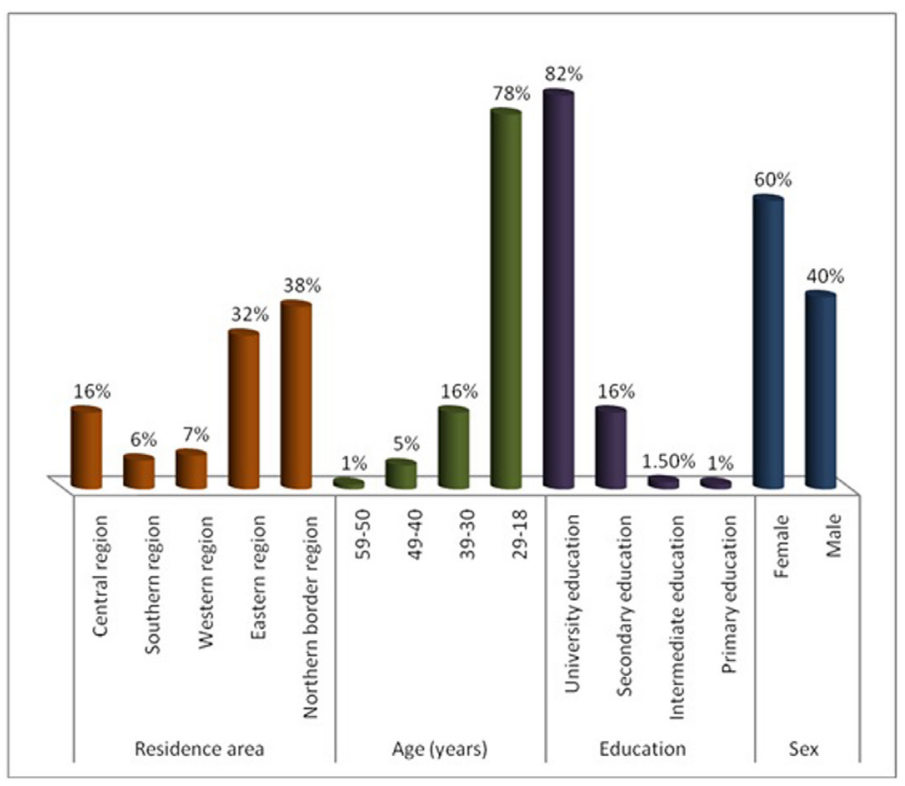

Figure 1: Demographic characteristic of participants. $(n=521)$ data analysis, neutral responses such as "not sure" or don't know were regarded as negative answer.

\section{RESULTS}

\section{Demographic characteristics of participants}

Demographic characteristics of the respondents, including gender, age, level of education and residential status are presented in Figure 1. A total of 521 general populations answered the questionnaire. From which the females represent $60 \%(311 / 521)$, majority of participants $(82 \%)$ were highly educated, also majority (78\%) were within the age range 18-29 years and in addition, $38 \%$ were from Northern Border Region.

\section{Awareness section}

The Awareness section consisted of three items that are assessing the level of knowledge about CRC. The majority of the participants (81\%) were heard of CRC. However, approximately (38\%) of the participants thought that colon cancer commonly found in Saudi Arabia, (32\%) heard about tests or examination that used in the detection of colon cancer (Figure 2).

The social media represent the main source of information for $24 \%$ $(120 / 521)$ of the study participants. $21 \%(109 / 521)$ of the participants had received information material regarding colorectal cancer within their school curriculum as presented in Table 1. 18\% (94/521) participants obtained their information from internet. Average score of good awareness about colorectal cancer was $50 \%$.

\section{Knowledge of Symptoms Section}

The awareness regarding symptoms section is shown in Figure 3. Approx one third of participants $(30 \%, 157 / 521)$ were recognized that colorectal cancer can possibly start without any obvious symptoms. $54 \%(282 / 521)$ of participants agreed that CRC may cause disturbances in the intestines as constipation or diarrhea. Of all the participants, $45 \%(237 / 521)$ agreed that anal bleeding can be a symptom of cancer of the colon and rectum. As for the fourth question in the symptoms section $41 \%(215 / 521)$ agreed that the presence of blood in the stool and change its color to the dark color is a symptom of cancer of the colon and rectum. 52\% (271/521) agreed that colorectal cancer may cause

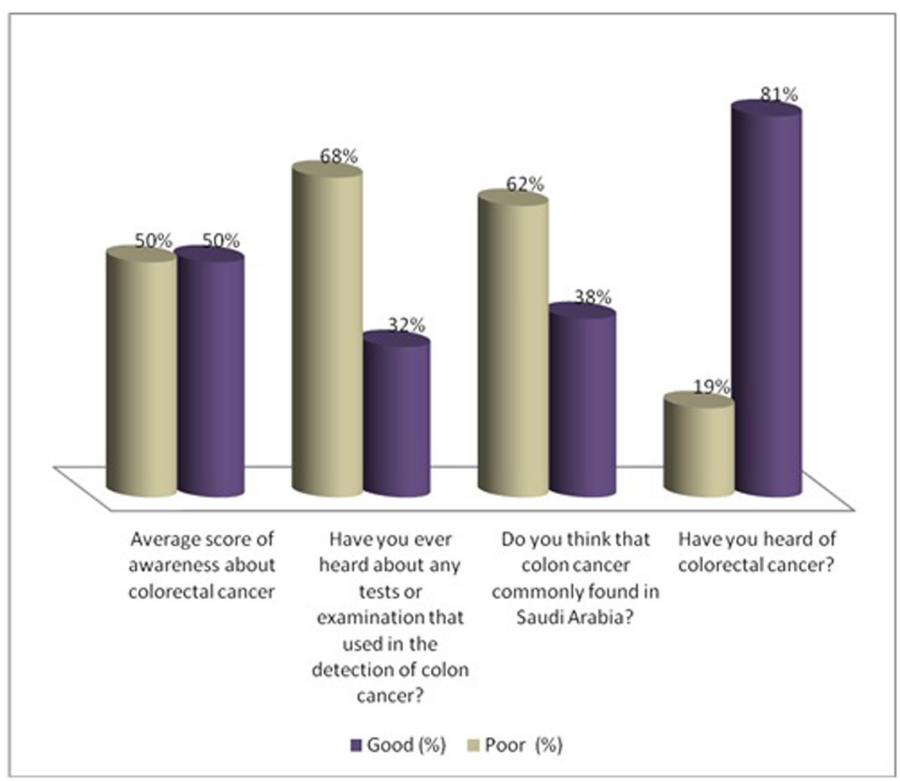

Figure 2: Responses of participants on Awareness section. $(n=521)$ 
cramps and abdominal pain. The last question in the symptoms section was held to assess the awareness regarding rapid descent of the weight without cause is a symptom of cancer of the colon and rectum and $45 \%$ $(237 / 521)$ of participant agreed.

\section{Knowledge about risk factors of CRC}

In the risk factors section presented in Figure 4a and 4b, 21\% (109/521) of participant believes that men are more likely to suffer from CRC. Regarding the existence of an acquired or hereditary defect in the gene may be the causes of cancer of the colon and rectum, 31\% (163/521) of the participant agreed with this fact and about 39\% (204/521) believe that polyps in the colon are an important factor in the incidence of colorectal cancer. The fourth question of risk factors section was inflamed colon are a risk factor for having colorectal cancer, 51\% (266/521) of the participant answered correctly. Regarding that fact that if one of the family members are suffering from colorectal cancer, then this will increase your chance of having that same illness, 34\% (179/521) of participant have agreed. 39\% $(206 / 521)$ of participants have agreed that smokers are more susceptible to have colorectal cancer, 29\% (153/521) believe that obese people are more likely to suffer from colorectal cancer. $46 \%$ (240/521) believe that low intake of fruit/vegetables is a risk factor for having colorectal cancer. $33 \%(174 / 521)$ believe that colorectal cancer risk increase with age.

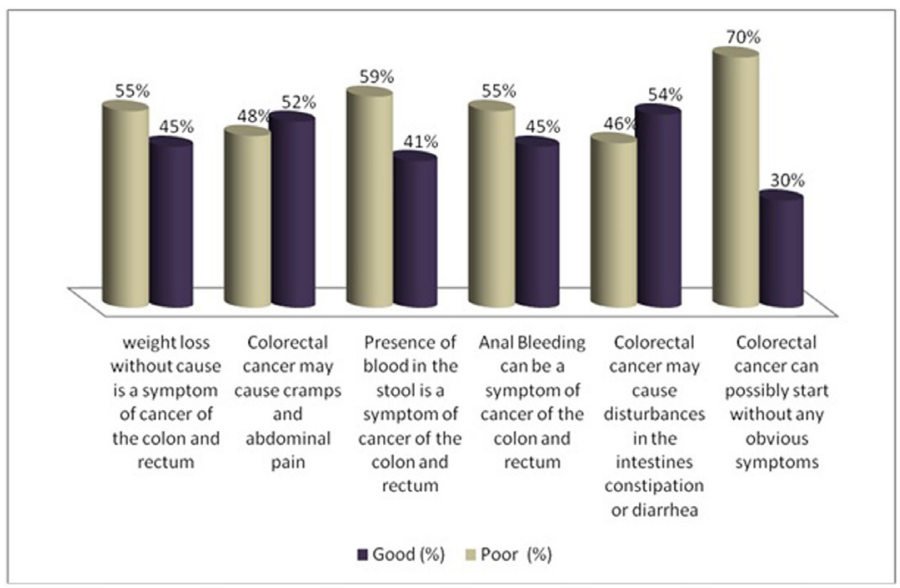

Figure 3: Knowledge about symptoms of colorectal cancer.
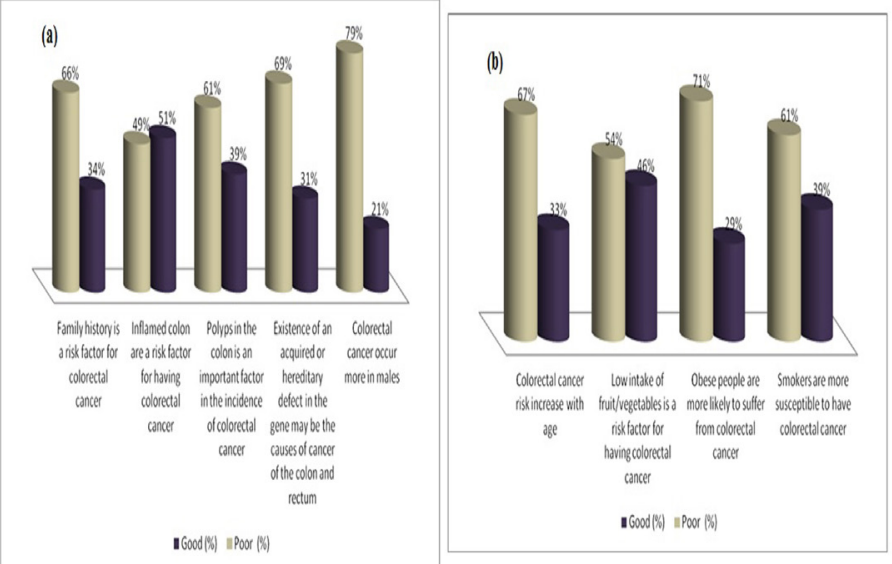

Figure 4: Knowledge about risk factors of colorectal cancer.

\section{Attitude regarding colorectal cancer screening}

This section contained three questions assessing the attitude of participants toward screening for colorectal cancer (Figure 5). 71\% $(368 / 521)$ of participants agreed that screening can find cancer early and treatment can be the most effective, $72 \%$ (375/521) agreed that late detection of late stage of bowel cancer carries poorest survival rate and $71 \%(368 / 521)$ of participants willing to have a screening test for the bowel cancer, even without any symptom. Average positive score of attitude toward screening for colorectal cancer was $41 \%$.

\section{DISCUSSION}

In order to set up an effective national colorectal cancer screening program, it is imperative to have a clear picture about the public knowledge about this cancer and their preference towards the screening program. This study was conducted with the aim to determine the level of awareness, knowledge and attitude toward colorectal cancer among Saudi people.

This study indicates that general awareness of CRC is 50\% among the population we sampled. Most had heard about CRC but were not able describe that CRC commonly found in Saudi Arabia and majority had not heard about any tests or examination that used in the detection of CRC. The social media advertising on CRC was significantly associated with greater awareness and higher overall CRC knowledge scores which is consistent with the previous findings on examining the effect of media on awareness. ${ }^{17,18}$ The second highest influence factors on awareness was study information material about CRC within their school curriculum which was also a major contributing in awareness. This study suggests a pivotal role of social media followed by study curriculum used in school education raising the level of awareness of CRC and confirm the

Table 1: Source of information about colorectal cancer. $(n=521)$

\begin{tabular}{cccc}
\hline Variable & Categories & Frequency & Percentage (\%) \\
\hline $\begin{array}{c}\text { Source of } \\
\text { information }\end{array}$ & Doctor/Pharmacist & 49 & $9 \%$ \\
& Study & 109 & $21 \%$ \\
& Internet & 94 & $18 \%$ \\
& Social Media & 120 & $24 \%$ \\
& TV And Radio & 24 & $5 \%$ \\
& Awareness Campaign & 29 & $6 \%$ \\
& Relatives and friends & 81 & $15 \%$ \\
\hline
\end{tabular}

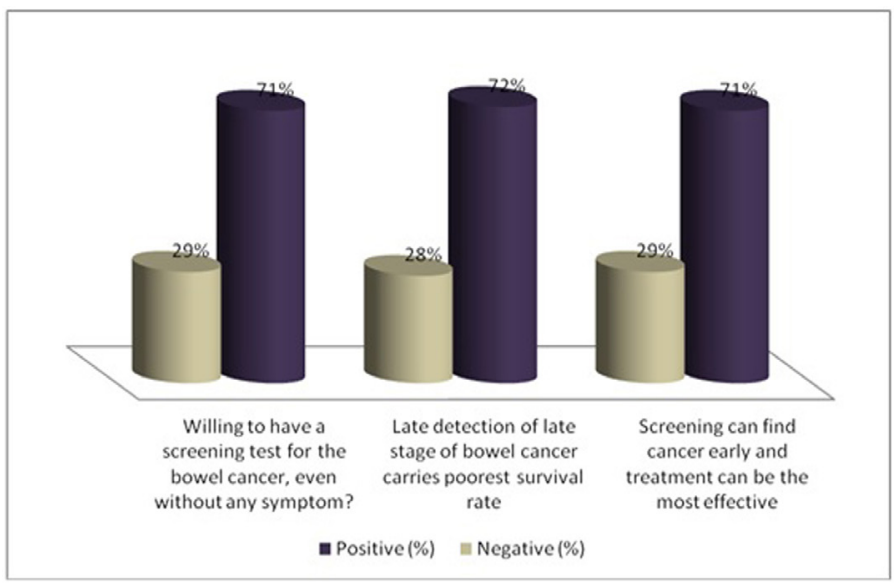

Figure 5: Responses for attitude regarding colorectal cancer screening. 
recommendations of its use to raise awareness and ultimately facilitate screening participation in Saudi Arabia.

The knowledge section consisted of several items those were assessing the level of knowledge regarding CRC. Responses to individual knowledge items including identification of risk factors and signs and symptoms are detailed in Figure 3 and Figure $4 a-b$. The average knowledge about symptoms was $44 \%$ and average score of good knowledge about symptoms was $44 \%$. However, that over half of participants did not know that weight loss without cause, presence of blood in the stool and anal bleeding can be a symptom of cancer of the colon and rectum which suggests this is an important concept to be emphasised in education and awareness campaigns.

Average knowledge about risk factors was found 38\% and average score of good knowledge about CRC was found $41 \%$ among study population. The knowledge among study participants on CRC was found low. This is based on low percentage of respondents that were aware about the symptoms and risk factors of the disease. Symptoms such as change in bowel habit, blood in the stool, weight loss and abdominal pain were recognized by small percentage of the respondents. These findings are consistent with some previous studies. ${ }^{19,20}$ Loh et al. 2013 in their community-based study carried out in five rural/suburban areas in which their findings showed that awareness of warning signs for CRC were poor. Most of their study respondents were only able to identify 2 or 3 of the nine warning signs listed. This result indicates the need for health promotion campaigns to contribute to a better awareness among public. ${ }^{21}$ In a recent survey from Saudi Arabia, including the general population, it was noted that knowledge and awareness about CRC were not adequate. ${ }^{22,23}$ This finding is in line with other studies conducted by Hilmi et al. 2010 and Su et al. 2013 which found much low awareness level about risk factors of colorectal cancer. ${ }^{24,25}$

A study from Taiwan found an increased risk for advanced cancer among immediate family members of colorectal cancer patient who has been screened ${ }^{26}$ Obesity was found to increase the risk of colorectal cancer. Ma et al. 2013 had conducted a systematic review on 54 studies assessing the association of obesity with the risk of colorectal cancer and concluded that both of general obesity (measured using Body Mass Index) and central obesity (measured using waist circumference) were highly linked to the colorectal cancer. ${ }^{27} \mathrm{CRC}$ incidence also strongly related to age. In the United Kingdom, over $70 \%$ of newly diagnosed colorectal cancer cases were among those aged 65 and older. ${ }^{28}$ Recently, local cancer registry observed similar trend in which more than $80 \%$ of colorectal cancer occur in people aged 50 or older. ${ }^{29}$ The same registry also documented the proportion of colorectal cancer increased with age, which peak between 60 and 64 for men and between 55 and 59 for women.

Consequently, failure to acknowledge these common risk factors could hamper the turn up for future colorectal cancer screening program. One of the solutions is to engage the primary care doctors and family physician in identifying and recommending high risk patients for colorectal cancer screening. The effectiveness of the family doctor's role has been proven in previous studies and should be the way forward to increase awareness and cancer screening uptake. ${ }^{30,31}$

Many studies found that positive family history of colorectal cancer as a motivational factor to undergo cancer screening test. ${ }^{32,33}$ Interestingly, a large percentage (71\%) of the studied population (368/521) willing to take the screening test even without any apparent symptoms which is consistent with previous studies conducted among Saudi general population. ${ }^{34,35}$ Such positive attitude indicates that the studied populations are ready and willing to participate in future colorectal cancer screening program.

\section{CONCLUSION}

This study is an attempt to identify the level of awareness among the Saudi people so that the results can be utilized to design measures to improve the awareness. In conclusion, we found that the majority of public had positive attitude toward concept of cancer screening but their knowledge and awareness about colorectal cancer was low which indicate the need for promotion of cancer education among public in order to reduce the incidence of CRC.Awareness actions are useful to clarify possible questions and information to the population in order to increase compliance with screening. It worth to establish health education campaign to increase awareness of CRC as it is one of the commonest cancers in Saudi Arabia. In order to make the future colorectal cancer screening programs successful, cancer educations should be promoted to public with more involvement from family physicians and primary care doctors.

\section{ACKNOWLEDGRMENT}

The authors would like to thank all the participants who took part in the study.

\section{CONFLICT OF INTEREST}

All authors declare that they have no conflict of interest.

\section{ABBREVIATIONS}

CRC: Colorectal Cancer; WHO: World Health Organization; FOBT: Fecal Occult Blood Testing; KSA: Kingdom of Saudi Arabia

\section{REFERENCES}

1. Ferlay J, Soerjomataram I, Dikshit R, Eser S, Mathers C, Rebelo M, et al. Cancer incidence and mortality worldwide: Sources, methods and major patterns in GLOBOCAN 2012. Int J Cancer. 2015;136(5):359-86.

2. International agency for research on cancer. World Cancer Report. 2014. Agency for research cancer international. http:// www.iarc.fr/en/publications/books/wcr/ wcr-order.php

3. Bazarbashi S, AlEid H, Minguet J. Cancer Incidence in Saudi Arabia: 2012 Data from the Saudi Cancer Registry. Asian Pac J Cancer Prev. 2017;18(9):2437-44.

4. Mandel JS, Church TR, Bond JH, Ederer F, Geisser MS, Mongin SJ, et al. The effect of fecal occult-blood screening on the incidence of colorectal cancer. $\mathrm{N}$ Engl J Med. 2000;343(22):1603-7.

5. Mack LA, Stuart H, Temple WJ. Survey of colorectal cancer screening practices in a large Canadian urban centre. Can J Surg. 2004;47(3):189-94.

6. Fedewa SA, Sauer AG, Siegel RL, Smith RA, Torre LA, Jemal A. Temporal Trends in Colon Cancer Screening among Asian Americans. Cancer Epidemiol Biomarkers Prev. 2016;25(6):995-1000

7. Folprecht G. PG 1.1 Epidemiology of Colon cancer: Risk factors, genetic predisposition. European Journal of Cancer. 2014;50:S1-]8

8. Siegel R, Desantis C, Jemal A. Colon cancer statistics, 2014. CA Cancer J Clin. 2014;64(2):104-17.

9. Alharbi RO. Colon cancer and Saudi population. Int J Cont Med Res 2017;4(8):1815-19

10. Arbyn M, Oyen VH, Lynge E, Micksche M, Faivre J, Jordan J. European Commission's proposal for a council recommendation on cancer screening. BMJ. 2003;327(7409):289-90

11. WHO. World Cancer Report 2014, in International Agency for Research on Cancer. WHO: Geneva. 2014.

12. Christou A, Thompson SC. Colorectal cancer screening knowledge, attitudes and behavioural intention among Indigenous Western Australians. BMC Public Health. 2012;12(1):528.

13. Misra S, Lairson DR, Chan W, Chang YC, Bartholomew LK, Greisinger A, et al. Cost effectiveness of interventions to promote screening for colorectal cancer: a randomized trial. J Prev Med Public Health. 2011;44(3):101-10.

14. Ibrahim EM, Zeeneldin AA, El-Khodary TR, Al-Gahmi AM, Bin SBM. Past, present and future of colorectal cancer in the Kingdom of Saudi Arabia. Saudi $J$ Gastroenterol. 2008;14(4):178-82.

15. Pinto CG, Paquete AT, Pissarra I. Colorectal cancer in Portugal. Eur J Health Econ. 2010;10(1):S65-73.

16. Al-Thafar AK, Al-Naim AF, Albges DS, Boqursain SK, Aldhafar AS, Ghreiz SM, et al. Knowledge Attitude and Practice of Colorectal Cancer among School 
Teachers in Al-Ahsa Saudi Arabia. Asian Pac J Cancer Prev. 2017;18(10):2771-4.

17. Al-Eid HS. Tables: Saudi Cancer Registry 2008, Riyadh, Main Office, National Cancer Registry. 2011;38-9.

18. Jemal A, Bray F, Center MM, Ferlay J, Ward E, Forman D. Global cancer Statistics. CA Cancer J Clin. 2011;61(2):69-90.

19. Hilmi I, Hartono JL, Goh K. Negative perception in those at highest risk--potential challenges in colorectal cancer screening in an urban Asian population. Asian Pac J Cancer Prev. 2010;11(3):815-22.

20. Loh KW, Majid HA, Dahlui M, Roslani AC, Su TT. Sociodemographic predictors of recall and recognition of colorectal cancer symptoms and anticipated delay in help- seeking in a multiethnic Asian population. Asian Pac J Cancer Prev. 2013;14(6):3799-804.

21. Wong MC, Hirai HW, Luk AK, Lam TY, Ching JY, Griffiths SM, et al. The knowledge of colorectal cancer symptoms and risk factors among 10,078 screening participants: are high risk individuals more knowledgeable?. PLoS One. 2013;8(4):e60366.

22. Imran M, Sayedalamin Z, Alsulami SS, Atta M, Baig M. Knowledge and Awareness of Colorectal Cancer among Undergraduate Students at King Abdulaziz University, Jeddah, Saudi Arabia: a Survey-Based Study. Asian Pac J Cancer Prev. 2016;17(5):2479-83.

23. Zubaidi AM, AlSubaie NM, AlHumaid AA, Shaik SA, AlKhayal KA, AlObeed OA. Public awareness of colorectal cancer in Saudi Arabia: A survey of 1070 participants in Riyadh. Saudi J Gastroenterol. 2015;21(2):78-83.

24. Hilmi I, Hartono JL, Goh K. Negative perception in those at highest risk--potential challenges in colorectal cancer screening in an urban Asian population. Asian Pac J Cancer Prev. 2010;11(3):815-22.

25. Su TT, Goh JY, Tan J, Muhaimah AR, Pigeneswaren Y, Khairun NS, et al. Level of colorectal cancer awareness: a cross sectional exploratory study among multiethnic rural population in Malaysia. BMC Cancer. 2013;13(1):376.
26. Tung SY, Wu CS. Risk factors for colorectal adenomas among immediate family members of patients with colorectal cancer in Taiwan: A case-control study. Am J Gastroenterol. 2000;95(12):3624-8.

27. Ma $Y$, Yang $Y$, Wang $F$, Zhang $P$, Shi $C$, Zou $Y$, et al. Obesity and risk of colorectal cancer: A systematic review of prospective studies. PLoS One. 2013;8(1):e53916.

28. Office for National Statistics. Cancer Registration Statistic 2012, England. In 'Statistical Bulletin'. 2014.

29. Radzi AHM, et al. The Second Report of the National Cancer Patient RegistryColorectal Cancer, 2008-2013, Kuala Lumpur, Malaysia.

30. Hewitson P, Ward AM, Heneghan C, Halloran SP, Mant D. Primary care endorsement letter and a patient leaflet to improve participation in colorectal cancer screening: results of a factorial randomised trial. $\mathrm{Br} J$ Cancer. $2011 ; 105(4): 475-80$

31. Weller DP, Patnick J, Mclntosh HM, Dietrich AJ. Uptake in cancer screening programs. Lancet Oncol. 2009;10:693-9.

32. Hlavaty T, Lukac L, Huorka M, Bezayova T, Duris I. Positive family history promotes participation in colorectal cancer screening. Bratisl Lek Listy. 2005;106(10):318-23.

33. Delgado-Plasencia L, López-Tomassetti-Fernández E, Hernández-Morales A, Torres-Monzón E, González-Hermoso F. Willingness to undergo colorectal cancer screening in first-degree relatives of hospitalized patients with colorectal cancer. J Med Screen. 2009;16(1):33-8.

34. Mosli MH, Al-Ahwal MS. Colorectal cancer in the Kingdom of Saudi Arabia: Need for screening. Asian Pac J Cancer Prev. 2012;13(8):3809-13.

35. Ravichandran K, Al-Hamdan NA, Mohamed G. Knowledge, attitude and behavior among Saudis toward cancer preventive practice. J Family Community Med. $2011 ; 18(3): 135-42$.

Article History: Submission Date : 09-04-2020; Revised Date : 20-05-2020; Acceptance Date : 22-07-2020

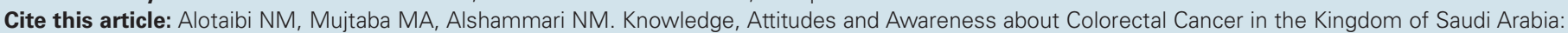
A Cross Sectional Study. J Young Pharm. 2020;12(3):266-70 